ISSN 0717 - 2877

Universidad de Talca - Facultad de Ciencias Jurídicas y Sociales

Gobierno de la supervisión y riesgo de captura en la Comisión para el Mercado Financiero tras la Ley № 21.000

Lusitania Villablanca Cerda

Trabajo recibido el 12 de diciembre de 2018 y aprobado el 15 de agosto de 2019

\title{
Gobierno de la supervisión y riesgo de captura en la Comisión para el Mercado Financiero tras la Ley № 21.000*
}

GOVERNMENT OF THE SUPERVISION AND RISK OF CAPTURE IN THE COMMISSION FOR THE FINANCIAL MARKET AFTER LAW № 21,000

LUSITANIA VILLABLANCA CERDA **

RESUMEN

Este texto analiza la Ley № 21.000 que creó la Comisión para el Mercado Financiero, dando vida a una nueva institucionalidad para la regulación de este, en remplazo de la Superintendencia de Valores y Seguros. El principal objetivo de dicha reforma era garantizar la independencia del regulador respecto de los poderes públicos y de los intereses privados. Lo anterior justifica realizar un análisis crítico de la ley, a fin de determinar si las reformas emprendidas satisfacen dicha ambición. Examinaremos así el tratamiento legal de todos aquellos factores que configuran la independencia del regulador, para compararla con la situación existente en forma previa a la reforma, y con los requerimientos que se formulan respecto de dicha garantía por la doctrina regulatoria, y el derecho comparado.

ABSTRACT

This text analyzes Law № 21,000 that created the Commission for the Financial Market, giving life to a new institution for the regulation of financial markets, in replacement of the Superintendence of Securities and Insurance. The main objective of this reform was to guarantee the independence of the regulator in relation to public powers and private interests. The foregoing justifies a critical analysis of the law, in order to determine whether the reforms undertaken meet this objective. We will thus examine the new regulation with regard to all those factors that configure the independence of the regulator, in order to compare it with the regulation prior to the reform, and with the requirements that are formulated with respect to said guarantee by regulatory doctrine and comparative law.

PALABRAS CLAVE

Reguladores, regulación, mercado financiero, independencia.

KEY WORDS

Regulatory, regulation, financial markets, independence.

\section{Introducción}

Plasmando una esperada modernización de nuestros mercados financieros ${ }^{1}$, con fecha 23 de febrero de 2017 se publicó la Ley № 21.000 (en adelante también, la Ley) que crea la Comisión

\footnotetext{
* Lusitania Villablanca Cerda manifiesta su agradecimiento al Sr. Matías Larraín, quien como ponente en el seminario “Procedimiento Sancionatorio Ley 21.000", de 24 de julio de 2017, organizado por el Centro de Regulación y Competencia (RegCom) se encuentra al origen de gran parte de las reflexiones contenidas en este texto.

** Lusitania Villablanca Cerda, abogado, Master en derecho de los mercados, de los negocios y de la economía, Doctor en derecho. Académico Universidad Mayor, Santiago, Chile. correo electrónico: lusitania.villablanca@gmail.com.

${ }^{1}$ Sobre la tramitación legislativa MORALES (2018), pp. 98 y ss.
} 
para el Mercado Financiero (en adelante, CMF) ${ }^{2}$. La ley perseguía dos objetivos ${ }^{3}$ : garantizar la independencia del regulador tanto como órgano encargado de la supervigilancia del sector financiero, tanto como órgano sancionador (faceta procesal de la independencia) 4 . En este texto, por razones de extensión, solo analizaremos el primer objetivo.

Los primeros estudios, nacionales e internacionales, y las iniciativas relativas a la modernización del Decreto Ley № 3538, de 1980 (en adelante DL № 3538), Ley orgánica que regulaba la SVS, estuvieron siempre orientados a reformar lo que la jerga regulatoria denomina como "gobierno de la supervisión" 5 , esto es el diseño institucional del regulador, en función de los niveles de autonomía e independencia respecto del gobierno central y de la industria regulada ${ }^{6}$. Se trataba de consagrar mecanismos que permitieran remediar dos grandes cuestionamientos que siempre han pesado sobre los reguladores económicos.

Uno dice relación con el cúmulo de funciones que reúnen los reguladores, y otro (consecuencia del primero) se refiere a la necesidad de contrarrestar el riesgo de captura que pesa sobre ellos, mediante la consagración de mecanismos que garanticen su independencia respecto de los poderes públicos y de los poderes privados económicos ${ }^{7}$.

Así fue puesto en evidencia por las recomendaciones formuladas por organismos internacionales como el Banco Mundial ${ }^{8}$.

En efecto, el hecho de concentrar las tres funciones propias de los poderes del Estado: elaboración de normas, fiscalización y eventual sanción, convierte al regulador ${ }^{9}$ en un ente preciado por el sector público y privado. Es este cúmulo de funciones el que da origen al denominado "riesgo

\footnotetext{
${ }^{2}$ Con fecha 13 de diciembre de 2017 se publicó en el Diario Oficial el DFL N 10 del Ministerio de Hacienda, el cual fija para el 14 de diciembre de 2017 la entrada en funcionamiento de la CMF y para el 15 de enero de 2018 la fecha de supresión de la Superinten dencia de Valores y Seguros. Entre ambas fechas tuvo lugar un período de implementación.

${ }^{3}$ En este sentido el mensaje del proyecto de ley que creó la CMF pone en relieve los dos aspectos que requerían reforma: i) Mejora del diseño orgánico del regulador, poniendo término a la concentración de funciones y asegurando el debido proceso (p. 4); ii) Necesidad de mejorar proceso administrativo sancionatorio (p. 7 y 8). En este texto obviaremos el análisis de las ventajas económicas que implica tener un mercado financiero cuya regulación se ajuste a los estándares internacionales y nos atendremos a lo estrictamente jurídico. Sobre las primeras: MORALES (2018), pp. 79 y ss.

${ }^{4}$ Las diversas facultades (normativas, ejecutivas y sancionatorias) reunidas en manos de un solo organismo, en tanto vulneración del principio de separación de funciones, tiene igualmente incidencia respecto de la garantía de imparcialidad del regulador, la que le es exigible como órgano sancionador. De esta forma, las medidas destinadas a consagrar la imparcialidad serán analizadas en otro texto.

${ }^{5}$ Por ejemplo: SUPERINTENDENCIA DE VALORES Y SEGUROS (2008), pp. 51 y 92 y ss. En 2008, el Ministerio de Hacienda anunció la presentación de una reforma a la estructura organizacional de la SVS estructurada sobre tres objetivos: i) modificar su estructura superior, pasando de una estructura unipersonal a una colegiada; ii) separar las funciones de dirección superior en dos órganos distintos: uno a cargo del ejercicio de la potestad sancionadora y el otro a cargo del ejercicio de la función de supervisión y normativa; y iii) reformar el mecanismo de designación y remoción de los miembros de los órganos superiores, pasando de un régimen de "exclusiva confianza" a uno de nombramiento mixto y remoción por causa fundada. MINISTERIO DE HACIENDA (2008); LARRAÍN (2010), pp. 396-397; INFORME DE COMISIÓN ESPECIAL INVESTIGADORA DE LA CÁMARA DE DIPUTADOS (2010). En el mismo sentido la Recomendación realizada por el Comité de Gobiernos Corporativos de la OCDE a nuestro país en 2011, en que, teniendo presente el hecho que el cargo de Superintendente es designado y discrecionalmente removido por el Presidente, sugirió la necesidad de "establecer un sistema de pesos y contrapesos que permita proteger a la SVS del riesgo de intervención política en el cumplimiento de sus decisiones". OCDE (2011), p. 12.

${ }^{6}$ MASCINDARO et al. (2011), p. 4. Tratándose de una autonomía legal (en oposición de constitucional) el legislador puede establecer diversos niveles de autonomía (intensidad variable). CORDERO (2012), pp. 23-24.

7 La noción de poderes privados económicos ha sido latamente desarrollada por el autor francés Gérard de Farjat, en obras tales como: DE FARJAT (2004) y DE FARJAT (2000).

${ }^{8}$ Así lo expresa el mensaje de la Ley, según el cual organismos internacionales habían manifestado la relevancia de avanzar en una mejora institucional que permita fortalecer la independencia y sus facultades regulatorias, de investigación y sanción, entre otras. Mensaje de la Ley $\mathrm{N}^{\circ} 21.000$, de 2017, p. 4. Similares recomendaciones formularon la Comisión de Supervisión y Regulación Financiera, conocida como Comisión Desormeaux y el Informe del Grupo de trabajo para el fortalecimiento institucional del mercado de capitales, en adelante, "el grupo de trabajo de 2015".

${ }^{9}$ En el derecho comparado se habla de "autoridades independientes", agencias regulatorias independientes (ARI) o "reguladores independientes", FRISON-ROCHE (2011); JACOBZONE (2005).
} 
de captura", tema que ha sido latamente analizado por la doctrina nacional y comparada ${ }^{10}$, por lo cual nos limitaremos a exponer solo los rasgos imprescindibles de la materia en lo que hemos denominado el "marco conceptual" de las mismas.

Para garantizar la independencia del regulador, la Ley № 21.000 se enfocó en dos reformas: modificar la arquitectura del regulador a fin de paliar el riesgo de captura por parte de los intereses políticos; y, regular el principio de la probidad y de la abstención con el mismo objetivo, pero respecto de la industria regulada.

En este texto planteamos que, si bien las medidas destinadas a garantizar la independencia del regulador son bienvenidas y suficientes en varios aspectos, se perdió la oportunidad de ir más allá e innovar tanto en la composición del órgano, como en la regulación del principio de la abstención, y en el régimen post empleo, a través de los mecanismos que, extraídos del derecho comparado, describiremos en este texto.

Como hemos señalado, tanto la profesionalización del regulador, como el cúmulo de poderes que ostentan, son las principales causas del riesgo de captura. Por ello, en forma previa al análisis de la Ley № 21.000, nos parece necesario explicar cómo es la búsqueda de eficacia de la función regulatoria la que explica, por una parte, que la regulación se deje en manos de entidades profesionales ${ }^{11}$, y por otra, que se confieran a estas un cúmulo de poderes.

\section{La eficacia como fundamento de la profesionalización y del cúmulo de poderes}

Lord Acton acuñó el aforismo "El poder tiende a corromper y el poder absoluto corrompe absolutamente"12. Dicha expresión ilustra el principal fundamento del principio de separación de funciones públicas (en adelante, funciones o facultades), piedra angular de los sistemas democráticos ${ }^{13}$.

Nos referimos a este principio porque las principales críticas que se realizan a la regulación económica contemporánea sostienen que ella lo vulnera, al conferir a los reguladores un cúmulo de facultades que pueden ser ejercidas de forma abusiva, en beneficio de otros poderes públicos o de la industria regulada.

Dichas críticas no han sido obstáculo para que la técnica siga siendo utilizada, bajo el argumento de que el cúmulo es necesario, algunos afirman que imprescindible ${ }^{14}$, para un ejercicio eficaz de la función regulatoria. Dicho de otra forma, sin el cúmulo de poderes los reguladores no podrían ejercer eficazmente su misión. Se oponen así, la búsqueda de eficacia en la regulación y el respeto del principio de separación de funciones, siendo, al parecer, la primera la que ha predominado.

En efecto, la eficacia de la función regulatoria ha sido el principal eje en torno al cual esta se ha articulado ${ }^{15}$; así, el diseño de la regulación económica contemporánea parece ser el resultado

\footnotetext{
${ }^{10}$ En este sentido ARCULUS (2005); BALDWIN Y CAVE (2012); BALDWIN Y MAC CRUDDEN (1987); CAMACHO (2005); CORDERO (2012) y CORDERO (2014); DÍAZ (2012); DU MARAIS (2009); GARCÍA, VERDUGO (2009a); GARCÍA (2009b); LARRAÍN (2012); VILLABLANCA (2011); VILLABLANCA (2012); GARCÍA Y VERDUGO (2010); GARCÍA Y SOTO (2009); MINISTERIO DE HACIENDA (2011) y MINISTERIO DE HACIENDA (2015); OCDE (2017a) y OCDE (2017b).

${ }^{11}$ GARCÍA (2009), pp. 23 y 24; FRISON-ROCHE (1995), p. 49.

12 "Power tends to corrupt, and absolute power corrupts absolutely". John Emerich Edward Dalkberg Acton.

13 "Locke planteaba la separación de los poderes, no solo por su eficacia sino en aras de la libertad. La desconcentración de las funciones era esencial para evitar el absolutismo, ya que creía que si aquellos que hacían las leyes a su vez las ejecutaban, esto podía llevarlos a excusarse de su cumplimiento o modificarlas para beneficio propio", DÍAZ (2012).

${ }^{14}$ Varios autores: CAMACHO (2007); ROMÁN (2007); LETELIER (2017); VALLEJO Y GUILOFF (inédito); CORDERO (2013).

${ }^{15}$ BALDWIN et al. (2012), pp. 319-320; BALDWIN y MAC CRUDDEN (1987); CORDERO (2013), p. 122; El profesor Cordero Quinzacara ha señalado refiriéndose al Derecho regulatorio: “En él existe claramente una visión marcada por las ventajas del mercado y el desarrollo de
} 
de una batalla ideológica librada entre el Estado como titular de la soberanía ejercida a través de sus órganos y el Mercado, entendido como grupos de intereses que representan a las grandes empresas y que defiende la autorregulación, girando el punto en disputa en torno a cuál es el sistema regulatorio más eficaz para mercados particularmente complejos, como lo son los mercados regulados ${ }^{16}$.

Dicha confrontación se ha traducido, prácticamente en todos los países, en una solución de equilibrio consistente en sustraer dichas funciones de la competencia de los entes estatales que las ejercen de forma natural para delegarlas, normalmente de forma copulativa, a entes autónomos y profesionales, denominados reguladores económicos. Dicha solución se basa en la convicción de que los reguladores como entidades profesionales o técnicas, más que políticas, estando debidamente supervisadas, son capaces de tomar decisiones con prescindencia de los intereses o consideraciones políticas de turno, obedeciendo a una mirada a largo plazo ${ }^{17}$.

Así, los reguladores de los mercados financieros comparados son titulares de un poder normativo ${ }^{18}$ por cuanto dictan normas de alcance general en el mercado, las que pueden recibir distintas denominaciones. En Chile se les conoce bajo la denominación de normas de carácter general (NCG, denominación usada en la antigua SVS), circulares, oficios circulares, etc. En otras ocasiones dichas normas aparecen agrupadas en cuerpos más generales como la Recopilación actualizada de normas de la Superintendencia de Bancos e Instituciones Financieras (en adelante, SBIF).

Se afirma igualmente que los reguladores ejercen una función sancionadora-jurisdiccional ${ }^{19}$ por cuanto están facultados para aplicar sanciones como multas ${ }^{20}$ o la revocación de licencias, o autorizaciones necesarias para el ejercicio de ciertas funciones ${ }^{21}$.

Y no se trata de sanciones menores, la revocación de licencias implica derechamente impedir al agente económico del mercado regulado seguir participando en el mismo, la suspensión de operaciones se puede traducir en enormes pérdidas económicas mientras esta dure, y tratándose de multas, la envergadura de algunas de ellas, aplicadas en nuestro país es incuestionable. Tengamos presente que en el conocido como caso Cascadas ${ }^{22}$, la SVS aplicó una multa que alcanzó los 180 millones de dólares, mientras que la SBIF, en diciembre de $2015^{23}$, aplicó en el caso CORPBANCA, una multa que alcanzó los 30 millones de dólares ${ }^{24}$.

técnicas de intervención a partir de las fallas del mismo. Su visión parte desde la libertad económica, la libre competencia y la intervención mínima o, si se quiere, necesaria en razón de los fines que debe satisfacer el Estado", CORDERO (2013), p. 122.

${ }_{16}^{16}$ CORDERO (2013), p. 122.

${ }^{17}$ GARCÍA (2009), pp. 23 y 24; FRISON-ROCHE (1995), p. 49.

${ }^{18}$ CAMACHO (2005).

${ }^{19}$ CAMACHO (2007), p. 11; CORDERO (2014).

${ }^{20}$ Art. $36 \mathrm{~N}^{\circ} 2$ y $37 \mathrm{~N}^{\circ} 2$ de la Ley N²1.000, de 2017 tratándose de la CMF, Art. 19 del DFL Nº 3, de 1997, Ley General de Bancos (en adelante, LGB), tratándose de la SBIF.

${ }^{21}$ Art. 26 bis, 32, 50 y 130 de la LGB, de 1997 tratándose de la SBIF y $36 \mathrm{~N}^{\circ} 3$ y $37 \mathrm{~N}^{\circ} 3$ de la Ley N²1.000, de 2017 tratándose de la CMF. ${ }^{22}$ Resolución SVS N²23 de 2 de septiembre de 2014

${ }^{23}$ Durante la redacción de este texto, la multa fue rebajada por el Tribunal Constitucional, señalando que la sanción "se escapa a la razonabilidad y proporcionalidad, dado que dicho quantum sólo se alcanza en virtud de un ejercicio arbitrario que vulnera el anotado principio de proporcionalidad", de esta forma, si la Corte de Apelaciones ratifica la multa aplicada por la SVS, la sanción máxima que se podría aplicar es de 15.000 UF (US\$640 mil), que podría llegar hasta 75 mil UF (US\$3,3 millones) en caso de reincidencia, según lo establece el Art. 28 del DL 3538, de 1980, Ley Orgánica de la SVS, actual CMF. Tribunal Constitucional, Rol № 3236-16, 24 de mayo de 2018.

${ }^{24}$ Resolución SBIF № 16.191 de 30 de diciembre de 2015. 
No obstante, la legitimidad del poder de sanción en manos de los reguladores ha terminado por ser aceptada siendo su principal fundamento el mismo que justifica el cúmulo de funciones, esto es que dicho poder constituye una necesidad de la regulación económica ${ }^{25}$.

El poder de sanción se ve complementado por la función/poder de fiscalización o supervisión, función también llamada de policía ${ }^{26}$, la que, si se quiere clasificar dentro de las funciones tradicionales del Estado, corresponde a la función ejecutiva. En virtud de dicho poder los reguladores están facultados para autorizar la entrada al mercado de agentes económicos, por ejemplo, mediante el otorgamiento de licencias que permiten desempeñarse como corredor de bolsa o agente de valores ${ }^{27}$, y empresas de auditoría externa ${ }^{28}$.

Ejerciendo otra suerte de función ejecutiva los reguladores cuentan con la facultad de conducir las relaciones internacionales con organismos homónimos y aún más allá, de comprometer al Estado en la suscripción de memorándums de entendimiento o $\mathrm{MOU}^{29}$, o de acuerdos de divulgación de información con sus pares extranjeros. Se les permite integrar organizaciones internacionales ${ }^{30}$, por ejemplo: la International Organization of Securities Commissions (IOSCO), el Council of Securities Regulators of the Americas (COSRA), Financial Stability Board (FSB), la Internacional Association of Insurance Supervisors (IAIS), y la Organización para la Cooperación y el Desarrollo Económico (OCDE), entre otras.

De esta manera, antes de la reforma en estudio, se constataba la existencia de una serie de funciones reunidas en una sola mano, ejercidas por una autoridad unipersonal, cuyo nombramiento dependía de la exclusiva confianza del presidente de la República ${ }^{31}$.

Como consecuencia de lo anterior, se generaban una serie de riesgos, denominados por un autor como "anomalías constitucionales" 32 , entre los cuales se encontraba especialmente el riesgo de captura del regulador ya sea por parte del poder político, ya sea por parte de la industria regulada.

Entendiendo entonces, que el cúmulo de funciones es imprescindible para el ejercicio de la función regulatoria, se planteó el desafío de diseñarlo de tal forma que se disminuya el riesgo de captura del regulador. En efecto, se da por entendido que toda persona que ejerce una potestad puede hacer un uso abusivo de esta en beneficio/perjuicio de terceros, riesgo que obviamente se acrecienta cuando las funciones se encuentran acumuladas. En los párrafos siguientes expondremos el marco conceptual del riesgo de captura y su tratamiento por la Ley № 21.000 , comenzando por la captura por parte de los intereses políticos, y siguiendo con la captura por los intereses de la industria regulada.

\footnotetext{
25 "En este contexto, la sanción administrativa es un instrumento ineludible del Derecho regulatorio, transformándose en una de las medidas que viene a cerrar la variedad de técnicas de intervención de los órganos reguladores". CORDERO (2013), p. 142; CAMACHO (2005 - 2007); ROMÁN (2007); LETELIER (2016); VALLEJO Y GUILOFF (inédito); SOTO (2016).

${ }^{26}$ Esta última suele ser definida como "aquella actividad que la Administración despliega en el ejercicio de sus propias potesta des y por la cual, para garantizar el mantenimiento del orden público, limita los derechos de los administrados mediante el ejercicio de la coacción sobre los mismos. En otros términos, en ejercicio de la actividad de policía la Administración opera controlando las actividades de los particulares para que su libre desarrollo se acomode al bien público; para ello ejerce limitaciones, impone conductas y ajusta aquéllas a las exigencias del interés general”, GARRIDO (1959), p. 54; “(...) la regulación se superpone con las formas de intervención basadas en la actividad de policía y de servicio público, pero a partir de una perspectiva distinta: se trata de corregir las fallas de mercados, de manera que las medidas que comprende encuentran en aquello su justificación", CORDERO (2013), p. 142.

${ }^{27}$ Art. 24 inciso final, y art. 26 de la Ley № 18.045, de mercado de valores (en adelante, LMV, de 1980) y 5 № 15 de la Ley № 21.000 , de 2017.

${ }^{28}$ Art. 240 LMV, de 1980.

${ }^{29}$ Art. 4 letra s) Ley № 18.046 , de 1980.

${ }^{30}$ Art. 5 № 22 de la Ley № 21.000 , de 2017.

${ }^{31}$ Art. 7 DL NNo 3538, de 1980 para la SVS, Art. 82 de la LGB.

32 DÍAZ DE VALDÉS (2010).
} 


\section{Gobierno de la supervisión y captura del regulador por los poderes políticos}

En los párrafos siguientes expondremos cómo el diseño orgánico del regulador es fundamental para disminuir su riesgo de captura por parte de otros poderes del Estado y luego, las medidas que la Ley № 21.000 adoptó a este respecto.

\subsection{Marco conceptual del riesgo de captura por los poderes políticos}

En este ámbito, la captura del regulador ${ }^{33}$ puede tener lugar como consecuencia del régimen orgánico en lo relativo al nombramiento, a la composición y a la reglamentación del término de funciones del regulador ${ }^{34}$. Dicha captura puede también tener lugar como consecuencia de los objetivos estatutarios que la legislación les encomienda.

Refiriéndose al régimen orgánico, David Arculus señala:

when we speak of 'independent' regulators, what do we mean? There is statutory independence from government, giving freedom to operate without political interference, but also financial independence, personnel independence, operational independence and enforcement independence - which often need to be earned if the regulator is to have credibility with stakeholder ${ }^{35}$.

De esta forma, el primer aspecto que se analiza es el nombramiento y composición donde las posibilidades son: un regulador unipersonal o bien colegiado; que su nombramiento dependa de una o bien, de varias autoridades; $y$, finalmente, que el término de sus funciones esté debidamente reglamentado por el legislador o bien, que este quede a la discreción de otra autoridad.

La segunda hipótesis de conflicto de interés está dada por el hecho de que el regulador cumple su misión en la medida en que vela por el cumplimiento de sus objetivos estatutarios, esto es resguardar el sector económico que se le ha encomendado.

En Chile, el Art. 3 de la Ley confiere a la CMF, en términos generales, la misma competencia antes dada a la SVS y a la SBIF encomendándole fiscalizar a los diversos intervinientes en el mercado de valores y seguros (intermediarios, bolsas, fondos que la ley somete a su fiscalización y las sociedades que los administren, entre otras) y en el mercado de los bancos e instituciones

\footnotetext{
${ }^{33}$ En Estados Unidos el \$200.58 contenido en la Subpart Cel Maintenance of independence del Subpart C-Canons of Ethics del Title 17 Part 200, Chapter II, Part 200 del eCode of Federal Regulation (eCFR) señala: "Esta comisión ha sido establecida para administrar las leyes promulgadas por el Congreso. Sus miembros son nombrados por el presidente por y con el consejo y consentimiento del Senado para cumplir con los términos estipulados por la ley. Sin embargo, conforme a la ley, esta es una Agencia independiente y, en el desempeño de sus deberes, los miembros deben mostrar un espíritu de independencia firme y rechazar cualquier esfuerzo de los representantes de las ramas ejecutiva o legislativa del gobierno para afectar su determinación independiente de cualquier asunto que sea considerado por esta comisión. Un miembro no debe dejarse llevar por las demandas partidistas, el clamor público o las consideraciones de popularidad o notoriedad personal; así también él debería estar por encima del miedo a las críticas injustas de cualquiera". El artículo 9 de la Loi 201755 francesa señala: "En el ejercicio de sus poderes, los miembros de las autoridades administrativas independientes y las aut oridades públicas independientes no reciben ni solicitan instrucciones de ninguna autoridad. Los miembros de las autoridades administrativas independientes y las autoridades públicas independientes no asumen, a título personal, una posición pública perjudicial para el correcto funcionamiento de la autoridad a la que pertenecen".

${ }^{34}$ La OCDE señala que los "puntos críticos" que pueden surgir a lo largo del ciclo de vida de un regulador y que presentan mayor potencial de influencia indebida son: claridad de roles, transparencia y rendición de cuentas, independencia financiera, independencia del equipo directivo y comportamiento del personal. OCDE (2017a).

${ }^{35}$ ARCULUS (2005), p. 50. Ver por ejemplo la solicitud presentada por los cinco Comisionados de la SEC en la que pidieron a un Juez de Derecho Administrativo que presentara una declaración jurada que indicara si alguna vez ha experimentado una presión para decidir a favor de la SEC.
} 
financieras (empresas bancarias, empresas dedicadas a la emisión y operación de tarjetas de crédito, ciertas cooperativas de ahorro y crédito, entre otros).

Existiendo Superintendencias cuyas misiones u objetivos pueden superponerse entre sí, los reguladores, al tomar decisiones, pueden perjudicar los intereses de otros sectores económicos e incluso, el interés colectivo. Es lo que señala el informe final de la Comisión de Reforma a la Regulación y Supervisión Financiera cuando indica que "en ciertas circunstancias, algunos de los objetivos de política pública pueden entrar en conflicto. La forma en la cual los distintos modelos (de supervisión) resuelven dichos conflictos también permite establecer ciertas diferencias entre ellos" 36 .

Ejemplificando el conflicto entre distintos objetivos regulatorios se cita la corrida en contra del Banco Northern Rock en el Reino Unido, en la cual se opusieron los objetivos regulatorios propios de la regulación prudencial (la que vela por la solvencia de las instituciones reguladas), aquellos vinculados a la conducta de mercado (que vela por la integridad y eficiencia de los mercados), y los relativos a la protección al consumidor (especialmente en lo referido a una adecuada información). En tal caso, los dos últimos fueron privilegiados en desmedro del objetivo de supervisión prudencial ${ }^{37}$. La razón es simple: la conducta de mercado y la protección del consumidor reciben mayor atención de la ciudadanía y con ello, del mundo político.

Dichos casos han motivado la separación orgánica entre los reguladores que velan por la regulación prudencial o la solvencia, por un lado, y la conducta de mercado y la protección al consumidor, por el otro ${ }^{38}$. Dicha separación no ha operado en nuestro país, ni aún después de la Ley № 21.000 y $21.130^{39}$.

El conflicto entre objetivos regulatorios puede también darse entre reguladores o autoridades con distinta competencia. Por ejemplo, el conflicto producido en Chile, entre la Fiscalía Nacional Económica y la SVS, a propósito del supuesto monopolio ejercido por la Bolsa de Comercio de Santiago, y denunciado como tal por la Bolsa de Valparaíso ${ }^{40}$.

La existencia de objetivos regulatorios que pueden entrar en conflicto parece haber sido considerada por la Ley, desde el momento en que exigió que en el nombramiento de los comisionados "se vele de manera permanente por la conformación de un Consejo diverso y que equilibre la experiencia y conocimiento técnico que posean sus miembros sobre los mercados específicos que se encuentran sometidos a la fiscalización de la Comisión" ${ }^{\prime 1}$. Para el correcto entendimiento de la norma hay que tener presente que la CMF supervisa el mercado de valores, de seguros, y el sector bancario.

También podemos considerar que el legislador está consciente del conflicto de competencias que puede existir entre distintas autoridades, desde el momento en que agregó (artículo cuarto transitorio) en la ley № 19.880 que establece las bases sobre los procedimientos administrativos que rigen los actos de la administración del Estado, (en adelante, LBPA) el artículo 37 bis conforme al cual:

Cuando un órgano de la Administración del Estado deba evacuar un acto administrativo de carácter general que tenga claros efectos en los ámbitos de competencia de otro órgano, le remitirá todos los

\footnotetext{
${ }^{36}$ COMISIÓN DE REFORMA A LA REGULACIÓN Y SUPERVISIÓN FINANCIERA (2011), p. 26.

${ }^{37}$ COMISIÓN DE REFORMA A LA REGULACIÓN Y SUPERVISIÓN FINANCIERA (2011), p. 54.

${ }^{38}$ Australia, Canadá, Holanda y, más recientemente, Reino Unido. Las legislaciones de Francia, España, Italia y Portugal también han adoptado algunas de sus características. COMISIÓN DE REFORMA A LA REGULACIÓN Y SUPERVISIÓN FINANCIERA (2011), p. 33.

${ }^{39}$ Ley que moderniza la legislación bancaria, publicada en el Diario Oficial el 12 de enero de 2019.

40 SUPERINTENDENCIA DE VALORES Y SEGUROS (2013).

${ }^{41}$ Artículo 9 de la Ley № 21.000, de 2017.
} 
antecedentes y requerirá de éste un informe para efectos de evitar o precaver conflictos de normas, con el objeto de resguardar la coordinación, cooperación y colaboración entre los órganos involucrados en su dictación.

\subsection{Las medidas de la Ley № $\mathbf{2 1 . 0 0 0}$ contra el riesgo de captura por los poderes públicos}

En la mayoría de los estudios y proyectos que precedieron la dictación de la Ley y que le sirvieron de fundamento, se apuntaba primordialmente a dotar al regulador de garantías de independencia respecto de los poderes públicos ${ }^{42}$. Entre los factores corrientemente evocados a la hora de medir la independencia del regulador a este respecto $y$, por consiguiente, de evaluar su riesgo de captura se encuentran: su composición (unipersonal o colegiada), la duración del mandato de quienes la dirigen, lo que se relaciona directamente con la existencia de un régimen de exclusiva confianza o de remoción causada, su régimen financiero y la posibilidad de renovar los cargos superiores $^{43}$.

\subsubsection{De una autoridad unipersonal a un cuerpo colegiado}

El cambio esencial que demandaba nuestro sistema era pasar de una autoridad unipersonal a un gobierno por un cuerpo colegiado, $\mathrm{y}$, a modificar la naturaleza de los cargos desde un régimen de exclusiva confianza a un régimen de remoción causada ${ }^{44}$. Por otra parte, la dirección superior de la CMF está a cargo de un consejo (artículo 8), el cual ejerce las atribuciones que se le encomiendan, entre ellas, la facultad sancionatoria. De esta forma, los comisionados forman parte específicamente, del consejo.

La colegialidad del regulador era reclamada apelando a diversos argumentos, siendo el más recurrente el disminuir el riesgo de captura ${ }^{45}$; en efecto se entiende que capturar a un sujeto, como en el caso de las autoridades unipersonales, es más fácil que capturar a varios, razón que ha llevado a que la gran mayoría de los reguladores comparados sean órganos colegiados ${ }^{46}$.

En el sentido se enmarcan las reformas emprendidas en materia de justicia contenciosa administrativa, principalmente en el campo económico: Fiscalía Nacional Económica y Tribunal de la Libre Competencia ${ }^{47}$, Servicio de Impuestos Internos y Tribunales Tributarios y Aduaneros ${ }^{48}$, Tribunales de compras ${ }^{49}$ y Tribunal de propiedad industrial ${ }^{50}$.

Recordemos que la independencia responde también a la búsqueda de eficacia en el ejercicio de la función reguladora, la que exige otorgar mayores facultades al regulador. Dicho de

\footnotetext{
42 "Hasta la caída de Lehman Brothers y el comienzo formal de la crisis financiera en septiembre de 2008, la idea de introducir mejoras en la estructura organizacional de los reguladores financieros en Chile se había enfocado casi exclusivamente en analizar e intentar resolver los riesgos de interferencia política, captura y/o falta de independencia propios de su estructura organizacional”, LARRAÍN (2010), p. 393.

${ }^{43}$ El profesor Pierry considera los siguientes factores: designación y remoción de sus autoridades, mayor o menor control de tutela y, financiamiento independiente. PIERRY (1986), p. 427; VILLABLANCA (2011).

${ }_{44}$ Sobre los fundamentos de este cambio GARCÍA (2009); LARRAÍN (2010); VILLABLANCA (2011); LIBERTAD Y DESARROLLO (2009); RAMÍREZ (2000), p. 5; LARRAÍN (2014).

45 JACOBZONE (2005), p. 84.

${ }^{46}$ Estados Unidos, Reino Unidos, Francia, Canadá, entre otros.

${ }^{47} \mathrm{DL} \mathrm{N}^{\circ} 211$, de 1973.

${ }^{48}$ Ley № 20.322, de 2009.

${ }^{49}$ Ley № 19.886, de 2003 .

50 Ley 19.996, de 2005.
} 
otra forma, la independencia es la contrapartida necesaria del otorgamiento de facultades como la interceptación de llamadas y correspondencia y el acceso a la información bancaria ${ }^{51}$.

Bajo el régimen anterior, el regulador era presidido por una sola persona, el Superintendente, nombrado por el presidente de la República (en adelante, el presidente) a través de un decreto emanado del ministro bajo la dependencia del cual se encontraba, en nuestro caso, el Ministro de Hacienda. El término de las funciones del Superintendente no estaba reglamentado, dependiendo de la exclusiva confianza del presidente. Todo lo anterior lo volvía altamente susceptible a la influencia política del ejecutivo.

Hoy, la CMF es un cuerpo colegiado, cuyo titular, si bien es nombrado por el presidente de la República, tiene un mandato cuya duración está dada por la Ley. Lo mismo respecto de los cuatro miembros restantes.

Este cuerpo colegiado está compuesto de cinco miembros, cuyo presidente es nombrado por el presidente de la república ${ }^{52}$ de manera discrecional, mientras que los cuatro restantes requieren la ratificación del Senado por los cuatro séptimos de sus miembros en ejercicio ${ }^{53}$.

Dichas medidas son loables, sin embargo, existen alternativas, así, en Francia, intervienen otros poderes públicos, en el nombramiento de los comisionados, como el poder judicial, además de preverse un número mayor de comisionados, y de nombrar representantes de la industria regulada.

En cuanto a la duración en el cargo y posibilidad de renovarlos, esta es de seis años, pudiendo ser reelegidos solo por un nuevo período consecutivo. Se renuevan en pares, cada tres años. Anteriormente, si bien la ley únicamente señalaba que se trataba de un cargo de exclusiva confianza del presidente, la duración del cargo del Superintendente era, en la práctica, de 4 años, el mismo periodo de duración del mandato del presidente de la República.

Finalmente, se consagra un régimen de inamovilidad o de remoción causada, cuestión de alta relevancia por cuanto existe la convicción de que la independencia y autonomía política de los órganos se juega fundamentalmente en su inamovilidad.

\subsubsection{Presupuesto, libertad para organizar los servicios y rendición de cuentas}

La forma cómo el regulador obtiene sus recursos y la libertad que se le confiera para asignarlos es un aspecto fundamental para el análisis del grado de independencia del regulador ${ }^{54}$. Así lo manifiesta la última versión en línea del ICT Regulation Toolkit55: "The source of a regulatory authority's funds and the process by which these funds become part of the authority's actual budget can directly impact the degree of a regulator's autonomy and competence when carrying out its responsibilities."

\footnotetext{
${ }^{51}$ En este sentido ver el Mensaje Ley № 21.000, de 2017, p. 7.

${ }^{52} \mathrm{El}$ nombramiento por parte del presidente se justifica pues él permitiría "obtener cierta congruencia entre los objetivos de política pública perseguidos por el Gobierno y la orientación, dentro de su independencia, que debería tener la gestión de la agencia", MINISTERIO DE HACIENDA (2011).

53 Esta forma de nombramiento se ajusta a los estándares internacionales: Estados Unidos respecto de la Securities and Exchange Commission; la Comisión Nacional del Mercado de Valores de España; el Financial Policy Committee (FPC) y el Prudential Regulation Committee (PRC) en Inglaterra, entre otros. Sin embargo, se entiende que asegura aún más la independencia, el nombramiento por comisiones de expertos, en conjunto con el ejecutivo y el regulador. OCDE (2017b).

54 “Ni el reforzamiento del gobierno corporativo, ni la modificación de la regulación tendrían éxito si las agencias no dispusie ran de los recursos necesarios para dotarse de personal profesional calificado, tanto a nivel directivo, como en sus equipos profesionales". MINISTERIO DE HACIENDA (2011); MINISTERIO DE HACIENDA (2015); LARRAÍN (2010), p. 404.

${ }^{55}$ Módulo 6, sobre marco institucional y legal, párrafo, 6.5.1.2.
} 
El financiamiento mediante fondos públicos es consistente con el principio de unidad presupuestaria, pero "no favorece la planificación plurianual de las agencias ni contribuye a su autonomía operativa" ${ }^{56}$. En cuanto al financiamiento por parte de la industria regulada, a través del pago de tasas o tarifas regulatorias por los servicios que la autoridad le presta como inscripciones o autorizaciones, se le objeta el hecho de generar riesgos de captura del regulador, pero se valora el hecho de facilitar que los agentes de esta "internalicen los costos de producir una regulación y supervisión adecuada. Si se regula correctamente y sobre la base de criterios objetivos, su establecimiento no genera conflictos de interés o riesgo de captura para el regulador" 57.

Esta alternativa fue solo parcialmente recogida desde el momento en que, a diferencia de la regulación contenida en el Art. 16 del DL № 3538, los derechos percibidos ya no van a beneficio fiscal por lo que entendemos que pasarán a formar parte de su presupuesto anual.

Fuera de lo anterior, la nueva ley solo innovó en haber previsto en su Art. 6, la posibilidad de que nuevos recursos se le otorguen por leyes especiales o por aportes que pueda recibir a cualquier título por concepto de cooperación internacional ${ }^{58}$.

En cuanto a administración del presupuesto, el DL № 3538 sometía a la SVS a la fiscalización de la CGR respecto del examen de las cuentas de sus entradas y gastos, disposición que, no estando prevista en la nueva Ley, fue reintroducida por la Ley № 21.130 mediante la agregación de un inciso segundo al Art. 2. Dicha reincorporación es lamentable puesto que ella, común en materia de superintendencias, nunca ha logrado el efecto buscado, esto es mantener la fiscalización financiera excluyendo el control de legalidad ${ }^{59}$. En efecto, el Tribunal Constitucional la ha objetado por omitir funciones propias del organismo conferidas por la Constitución:

entre otras la principal de ellas consistente en el ejercicio del control de la legalidad que efectúa el Contralor General a través de la "Toma de razón" de los decretos y resoluciones de los organismos y servicios que forman la administración del Estado ${ }^{60}$.

Lo anterior se traduce en que la cláusula es inútil puesto que, cuando se ha aceptado su incorporación, por ejemplo en el caso de la Superintendencia de Pensiones, el Tribunal Constitucional ha señalado que tal limitación solo era constitucional si se interpretaba de forma de dejar incólume el control de legalidad general consagrado en el artículo 98 de la CP61.

Se lamenta igualmente que, habiendo elegido el financiamiento vía ley de presupuesto, no se haya recogido la recomendación del Informe del grupo de trabajo de 2015, en orden a "reducir el margen de discrecionalidad del Ejecutivo en la determinación del presupuesto de la Comisión, mediante la implementación de sistemas similares a los establecidos en la ley de Codelco" 62 o, habiendo seguido la línea propuesta por la OCDE en orden a establecer presupuestos plurianuales, a lo menos trienales ${ }^{63}$.

\footnotetext{
${ }^{56}$ MINISTERIO DE HACIENDA (2011), p. 40.

57 MINISTERIO DE HACIENDA (2015), p. 20.

${ }^{58} \mathrm{El}$ art. 1 inc. 3 del DL № 3538, de 1980 regulaba la materia: “Su patrimonio está integrado por los bienes que se le transfieren en virtud de este decreto ley, los fondos que anualmente destine al efecto la Ley de Presupuestos, los ingresos que perciba por los servicios que preste y los demás bienes que adquiera a cualquier título." El art. 8 del DL № 3538, de 1980 relativo a la dotación de personal y organización de los servicios se ve prácticamente reproducido por el art. 18 de la Ley № 21.000, de 2017.

59 DÍAZ DE VALDÉS (2010).

${ }^{60}$ Tribunal Constitucional chileno, Rol № 92-89, de 15 de enero de 1990, considerando séptimo.

61 Tribunal Constitucional chileno, Rol № 1032, de 4 de marzo de 2008, considerando decimosexto y decimoséptimo. Control de constitucionalidad del proyecto de ley, aprobado por el Congreso Nacional, sobre acceso a la información pública. Tribunal Constitucional chileno, Rol № 1051, de 10 de julio de 2008, considerando trigésimo tercero y trigésimo cuarto.

62 MINISTERIO DE HACIENDA (2015), p. 21.

${ }^{63}$ OECD (2017b).
} 
De esta forma no es posible afirmar que el legislador haya considerado el aspecto presupuestario como una cuestión relevante en el reforzamiento de la independencia del regulador, el que continúa siendo dependiente del poder ejecutivo, que es quien propone el presupuesto, y del legislativo, órgano encargado de aprobarlo64.

Finalmente, nos parece bienvenido que la Ley haya incorporado la rendición de cuentas (accountability) en el artículo 21 № 11, poniendo de cargo del consejo la elaboración de una cuenta pública anual que incluye materias como: las acciones de la Comisión en materia normativa y regulatoria, la cantidad de sanciones impuestas y sus causas, etc. Radica en el presidente de la CMF la obligación de publicar dicho informe.

\section{Gobierno de la supervisión y captura del regulador por los poderes privados económicos}

Al igual como procedimos respecto de la captura por los intereses políticos, en este párrafo expondremos las hipótesis de captura del regulador por la industria regulada y las medidas que la Ley № 21.000 adoptó a este respecto.

\subsection{Marco conceptual del riesgo de captura por los poderes privados económicos}

Actualmente, más que la captura por otros poderes públicos, se pone énfasis en el riesgo de captura por parte de la industria regulada, en función de la profesionalización del regulador ${ }^{65}$. Entendemos que existe un conflicto de interés cuando el regulador obtiene una ventaja, no necesariamente económica, como contraprestación a un ejercicio abusivo de sus funciones en beneficio de privados, ya sea que la obtenga durante el mismo mandato, o una vez que este ha finalizado.

El beneficio puede ser directo o indirecto, teniendo lugar este último, cuando la ventaja obtenida favorece a terceros que están vinculados al regulador por relaciones de familia, amistosas o profesionales.

Así resulta de la definición de conflicto de intereses contenida en la Ley № 20.880 sobre probidad en la función pública (en adelante, ley de probidad):

Existe conflicto de intereses en el ejercicio de la función pública cuando concurren a la vez el interés general propio del ejercicio de las funciones con un interés particular, sea o no de carácter económico, de quien ejerce dichas funciones o de los terceros vinculados a él determinados por la ley, o cuando concurren circunstancias que le restan imparcialidad en el ejercicio de sus competencias ${ }^{66}$.

En Francia, se estima que existe conflicto de intereses y que debe, en consecuencia, aplicarse el principio de la abstención, en "toda situación de interferencia entre un interés público e intereses públicos o privados que por su naturaleza pueda influir o parezca influir el ejercicio independiente imparcial y objetivo de una función". Dicha causal de abstención se aplica también

\footnotetext{
${ }^{64}$ Art. 67 CPR.

65 En Estados Unidos: "The SEC must recapture its activism of previous days. To do this, the Obama administration should appoint commissioners who believe that strong regulation benefits not only investors but, in the long run, the securities markets and the economy. These commissioners might come from the ranks of state securities commissioners, career SEC staff members, and academics", POSER (2009); DU MARAIS (2009), p. 31; GARCÍA Y SOTO (2009).

${ }^{66}$ Art. 1 inciso 3 de la Ley № 20.880, de 2016.
} 
cuando dicho interés ha existido dentro de los 3 años que preceden la deliberación, la verificación o el control ${ }^{67}$.

Una de las principales causas de riesgo está dada por la menor disponibilidad de recursos en el sector público ${ }^{68}$, y el hecho de que la preocupación del regulador por su avenir profesional, oriente el proceso de toma de decisiones.

Se sospecha así de una tendencia a favorecer a antiguos camaradas y clientes, ya que probablemente, en el futuro, vuelvan a tener dicha calidad; o de una tendencia a perjudicar a aquellas entidades o personas respecto de las cuales, antes de asumir el cargo, se encontraban en situación de competencia.

Al respecto, la Comisión Desormeaux señaló que el regulador podría hacer "mal uso de contactos e información obtenidos en el ejercicio de un cargo público. En efecto, el riesgo de captura se reduciría en la medida que los reguladores carecerían de incentivos para "mantener buenas relaciones" con entidades privadas reguladas que, en ausencia de la norma propuesta, pueden transformarse en empleadores del regulador a poco de concluir este sus funciones públicas" 69 .

Esas hipótesis sirven de fundamento al Art. 12 de la Convención de las Naciones Unidas contra la Corrupción en cuanto obliga a prevenir "la utilización indebida de los procedimientos que regulan a las entidades privadas, incluidos los procedimientos relativos a la concesión de subsidios y licencias por las autoridades para actividades comerciales". Se obliga además a prevenir los conflictos de intereses

imponiendo restricciones apropiadas, durante un período razonable, a las actividades profesionales de exfuncionarios públicos o a la contratación de funcionarios públicos en el sector privado tras su renuncia o jubilación cuando esas actividades o esa contratación estén directamente relacionadas con las funciones desempeñadas o supervisadas por esos funcionarios públicos durante su permanencia en el cargo.

En Chile, hay que sumar a los factores anteriores, los bajos sueldos y el hecho que, salvo por los avances introducidos por el Sistema de Alta Dirección Pública (SADP), no existen en nuestro país garantías de una carrera funcionaria; de esta forma es difícil conseguir que en la toma de decisiones el fiscalizador no tenga presente la perspectiva futura de volver al sector privado.

En los párrafos siguientes expondremos el sistema ideado por la Ley para contrarrestar los riesgos de captura, con la finalidad de juzgar su potencial eficiencia a la luz de los planteamientos de la teoría regulatoria y, cuando corresponda, del derecho comparado.

\subsection{Las medidas de la Ley № $\mathbf{2 1 . 0 0 0}$ contra el riesgo de captura por los poderes privados}

Recordemos tres afirmaciones realizadas: el conflicto de interés toma forma cuando el regulador obtiene una ventaja como contraprestación a un ejercicio abusivo de sus facultades; este beneficio puede tener lugar durante el ejercicio de sus funciones, o finalizado el mandato; en materia regulatoria es particularmente relevante el conflicto derivado de relaciones profesionales puesto que la profesionalidad del regulador se ha obtenido reclutando personal desde el sector regulado.

\footnotetext{
${ }^{67}$ Artículo 12 de Ley № 2017-55 sobre el estatuto general de las autoridades administrativas independientes y las autoridades independientes.

${ }^{68} \mathrm{En}$ el entendido que para reclutar profesionales de alta calidad se requiere generarles incentivos pecuniarios, el Art. 17 de Ley № 21.000, de 2017, incrementa el monto de las remuneraciones de los funcionarios de la CMF.

${ }^{69}$ COMISIÓN DE REFORMA A LA REGULACIÓN Y SUPERVISIÓN FINANCIERA (2011), p. 83.
} 
Las técnicas utilizadas por el legislador para regir la materia son: la consagración de nuevas causales de abstención (artículo 16); la remisión a las normas establecidas en la ley de probidad, c) la remisión a la LBPA lo que es especialmente relevante respecto del principio de la abstención; d) la consagración de interdicciones de empleo (exclusividad en el cargo), post empleo, participación social y lobby.

Respecto de la regulación de los conflictos de intereses que se traducen en una ventaja durante el ejercicio del cargo, la Ley solo se remitió expresamente a cuerpos normativos que ya eran aplicables a la SVS. Sí se innovó al consagrar medidas contra conflictos de intereses cuya contraprestación tendría lugar una vez finalizado el ejercicio del cargo, a través de las medidas post empleo. Esto es relevante, puesto que, en términos prácticos, la preocupación por el avenir profesional es una de las mayores fuentes de riesgo de captura.

\subsubsection{Normas de abstención y normas sobre probidad}

La probidad en la función pública se encuentra definida como un principio conforme al cual debe observarse "una conducta funcionaria intachable, un desempeño honesto y leal de la función o cargo con preeminencia del interés general sobre el particular" 70 .

La Ley hizo expresamente aplicables a los comisionados la ley de probidad y la LBPA (Art. 2 de la ley), las que contienen mecanismos que pueden prevenir y sancionar los conflictos de intereses privados. Pero se trata de una innovación menor por cuanto esas normas ya eran aplicables a la SVS en virtud de otros textos (Art. 4 № 1 de la ley de probidad, y Art. 2 inciso primero de la LBPA).

Dado el perímetro regulatorio en que los comisionados se desempeñan, es especialmente útil la obligación de declarar las actividades profesionales, laborales, económicas, gremiales o de beneficencia, sean o no remuneradas, incluyendo las realizadas en los doce meses anteriores a la fecha de asunción del cargo.

Por otra parte, la Ley № 21.130 incorporó un artículo 31 bis que dispone la obligación del personal de la Comisión de informar al presidente los créditos que soliciten en las empresas bancarias y otras instituciones sujetas a su fiscalización, así como los bienes que adquieran de tales empresas.

\subsubsection{Exclusividad en el cargo de comisionado}

El cargo de comisionado es de dedicación exclusiva (Art. 10), cuestión que no estaba prevista respecto del Superintendente. La Ley innovó así al señalar expresamente la incompatibilidad con todo cargo o servicio, sea o no remunerado, que se preste en el sector privado. Hagamos presente que la Ley № 18.834, Estatuto Administrativo, declara que los empleos regulados en dicha ley son incompatibles entre sí, y respecto de empleos o funciones prestadas al Estado, no previendo normas respecto del sector privado.

La Ley № 21.000, al igual que el Estatuto Administrativo, permite el ejercicio de actividades docentes en instituciones públicas o privadas hasta un máximo de doce horas semanales, pero la nueva ley incorpora una nueva excepción a la incompatibilidad de empleo al autorizar el desempeño en corporaciones o fundaciones, públicas o privadas, nacionales o extranjeras, cuando no persigan fines de lucro, y siempre que en ellas no perciban remuneración y que su desempeño no sea incompatible con sus funciones.

\footnotetext{
${ }^{70}$ Art. 1 inciso 2 de la Ley № 20.880, de 2016
} 
El respeto de las incompatibilidades antes aludidas puede ser verificado a través de la información que los comisionados deben proporcionar en virtud de la ley de probidad la que los obliga a efectuar una declaración de intereses y patrimonio, a delegar a terceros la administración de ciertos bienes y a, en ciertas situaciones, proceder a la enajenación de bienes que supongan conflicto de intereses.

En resumen, respecto del conflicto de interés durante el ejercicio del cargo, solo encontramos como innovación el artículo 31 bis, y la incompatibilidad acá analizada, en el resto la ley solo se remitió a cuerpos legales que ya eran aplicables a la SVS, radicando así, la verdadera novedad en la regulación de las actividades profesionales, una vez terminado el ejercicio del cargo.

\subsubsection{Interdicciones post empleo, participación social y Lobby}

En cuanto a las restricciones post empleo, antes de la dictación de la Ley, una medida destinada a evitar que el regulador financiero beneficiara a los privados, en resguardo de una carrera posterior, se encontraba en el Art. 56 de la Ley orgánica constitucional de bases generales de la administración del Estado (en adelante, LBGAE). El inciso final de dicha norma prohíbe, durante los 6 meses siguientes al término de las funciones, las actividades laborales de ex autoridades o funcionarios de una institución fiscalizadora en entidades del sector privado que hubiesen estado sujetas a la fiscalización de ese organismo.

Con la Ley se añaden tres nuevas restricciones post empleo. Algunas de ellas conciernen tanto a los comisionados como a los funcionarios de mayor jerarquía, y otras conciernen a todos los funcionarios de la CMF.

Se entiende por interdicciones post empleo la prohibición de prestar cualquier tipo de servicio, gratuito o remunerado, en entidades fiscalizadas ${ }^{71}$. La duración de la interdicción depende de la entidad con la que se tiene pensado entablar la relación laboral.

La interdicción más larga es de 6 meses y se aplica a entidades respecto de las cuales el ex comisionado o funcionario ejerció alguna de sus facultades dentro de los 12 meses anteriores al cese en su cargo (Art. 29 de la Ley). Por otro lado, se encuentran las entidades fiscalizadas por la $\mathrm{CMF}$, pero que no tuvieron vínculo con el ex comisionado durante el mismo plazo de 12 meses. En este último caso, la interdicción es de 3 meses (Art. 30 de la Ley).

Considerando la diversidad de facultades conferidas a la CMF, y el hecho de que muchas de estas las cuales no se traducen en una verdadera intervención de un consejero, la ley tuvo que especificar cuándo se iba a entender que el ex comisionado ha ejercido sus funciones respecto de una entidad fiscalizada: cuando de forma "específica, personal y directa"72, ha emitido actos, resoluciones o dictámenes; o ha participado en sesiones del Consejo en las que se hubiere adoptado algún acuerdo o resolución respecto de esas entidades; o cuando ha intervenido en los procedimientos administrativos, finalizados o no, que produjeron o producirán dichos actos administrativos. Reiteremos que, en este caso, la interdicción es de 6 meses y, destaquemos, que ella no concierne solo a los ex comisionados sino a todo funcionario del Servicio.

Respecto de todas las entidades con las cuales no existió la relación antes descrita, la prohibición es de 3 meses y se aplica a los ex comisionados y a los ex directivos pertenecientes al primer y segundo nivel jerárquico.

\footnotetext{
${ }^{71}$ Las entidades fiscalizadas por la Comisión se encuentran mencionadas en el Art. 3 de la Ley № 21.000, de 2017. Para efecto de las interdicciones de empleo, post empleo y lobby, el concepto de entidad fiscalizada comprende a las empresas que formen parte del mismo grupo empresarial conforme a la definición establecida en el Art. 96 de la LMV, de 1980. Art. 30 de la Ley № 21.000, de 2017.

${ }^{72}$ Art. 29 de la Ley № 21.000, de 2017.
} 
Paralelamente a la interdicción de empleo, y por el mismo plazo previsto para ellas, se prohíbe adquirir participación en la propiedad de las entidades sujetas a fiscalización de la Comisión, y en aquellas empresas que formen parte del mismo grupo empresarial de estas.

Una interdicción más extensa (dos años a contar del cese de sus funciones), se encuentra en el Art. 30 inciso final de la Ley la que concierne a los ex comisionados y ex funcionarios superiores antes aludidos. La prohibición les impide desarrollar actividades de lobby a favor de las entidades sujetas a fiscalización de la Comisión.

Dos medidas son previstas a fin de volver eficaz el régimen de incompatibilidad de empleo y post empleo. Una incitativa y otra disuasiva.

La medida incitativa sigue la línea del derecho comparado previendo una compensación a la interdicción post empleo, consistente en el derecho a percibir mensualmente de parte de la Comisión una compensación económica equivalente al $75 \%$ de la remuneración que les correspondía por el ejercicio de sus funciones ${ }^{73}$ (Art. 30 de la Ley), a menos que hayan cesado en sus cargos por destitución o por cualquier otra causal imputable a su conducta. Nos parece cuestionable que tal beneficio se restrinja a los ex comisionados y altos exfuncionarios antes definidos, pese a que todos los exfuncionarios son afectados por la interdicción prevista en el Art. 30 que es, además, la de más larga duración.

Como medida disuasiva nos referimos a la aplicación de multas tanto para los funcionarios que infrinjan las prohibiciones establecidas por la Ley, como para las personas naturales o jurídicas que establezcan los vínculos que dan lugar a la infracción.

Las multas oscilan entre las 50 y las 1.000 unidades tributarias mensuales (en adelante, UTM). La multa más baja, de 50 UTM, se aplica cuando el ex funcionario infringe la obligación de informar sus participaciones societarias y todas las actividades laborales y de prestación de servicios que realicen. Si dicha infracción es realizada por los ex comisionados y ex directivos pertenecientes al primer y segundo nivel jerárquico de la Comisión la multa puede alcanzar las 100 UTM.

Recordemos que la duración de las interdicciones de empleo depende de la importancia de la función que dio lugar a la interdicción. El resto de las multas a aplicar siguen el mismo esquema, así si se infringe la prohibición (de 6 meses) aplicable en relación con entidades respecto de las cuales se ejerció alguna facultad la multa puede alcanzar las 500 UTM, mientras que si se infringe la prohibición (de 3 meses) aplicable en relación con entidades respecto de las cuales no se ejerció alguna facultad, o la prohibición para desarrollar actividades de lobby, la multa puede alcanzar las 1.000 UTM.

Adicionalmente, los funcionarios infractores deben restituir lo percibido en virtud de la compensación económica a que da derecho la interdicción post empleo. La multa que se aplique a las personas naturales o jurídicas que contraten en infracción a lo dispuesto en la Ley es de hasta 4.000 UTM.

El Art. 29 inciso 20 de la Ley obliga a realizar una declaración jurada en la que se individualicen las entidades respecto a las cuales se configure la prohibición, dentro de los diez días hábiles siguientes al cese en sus funciones ${ }^{74}$.

Si bien las medidas antes descritas son loables, ellas podrían haber recibido un tratamiento más enérgico a fin de generar los efectos disuasivos e incitativos que se buscaban, por otra parte, el

\footnotetext{
${ }^{73}$ Toda remuneración que beneficie a los ex comisionados y altos funcionarios, que supere el $25 \%$ del promedio de la remuneración bruta mensual que recibían como remuneración en el CMF, debe deducirse de la compensación prevista en el Art. 30 de la Ley № 21.000 , de 2017.

${ }^{74}$ Una copia de dicha declaración deberá ser remitida al presidente de la Comisión y a la CGR, para su registro.
} 
plazo de 6 meses durante el cual dura la interdicción post empleo es demasiado breve debiendo haberse seguido lo propuesto por la Comisión Desormeaux (dos años) ${ }^{75}$.

Hagamos presente que el Art. 12 de la Convención de las Naciones Unidas contra la Corrupción obliga a imponer restricciones apropiadas durante un período razonable, por lo que el plazo de 6 meses no parece suficiente.

En el mismo sentido, la envergadura de las multas a aplicarse en caso de infracción a la interdicción post empleo, no parece proporcional a los montos que se manejan en estos mercados ${ }^{76}$.

Por otra parte, no vislumbramos razones para no haber seguido las recomendaciones tanto de la Comisión Desormeaux, como las contenidas en el Informe del Grupo de trabajo de 2015 en orden a mantener un $80 \%$ de la remuneración durante el período de prohibición a modo de indemnización o compensación, en efecto, el $5 \%$ de diferencia parece anodino.

La inclusión de datos inexactos o la omisión inexcusable de información relevante configura una causal de cesación en el cargo (Art. 13 inciso final de la Ley № 21.000), sin perjuicio de las sanciones establecidas en la Ley № 20.880, de 2003.

Considerando que este sistema no es eficaz si no se complementa con un procedimiento de vigilancia, nos parece que la gran falencia del régimen previsto es la ausencia de normas que permitan invocar la violación del deber de abstención, y que señalen cuales son las consecuencias procesales aplicables a las decisiones tomadas con infracción al deber de abstención.

A este respecto solo podemos recurrir a la LBPA que prevé una suerte de procedimiento de recusación al señalar que "En los casos previstos en los incisos precedentes podrá promoverse inhabilitación por los interesados en cualquier momento de la tramitación del procedimiento"77.

Más cuestionable aún es el inciso que precede a la norma recién citada, y que señala: "La actuación de autoridades y los funcionarios de la Administración en los que concurran motivos de abstención no implicará, necesariamente, la invalidez de los actos en que hayan intervenido" 78 . Entendiendo que las actuaciones de los funcionarios en procedimientos en los que concurren causales de abstención no necesariamente son inválidos, nos preguntamos cuales son las otras condiciones que se deben reunir para estimar que existe tal invalidez.

No podemos dejar de reconocer cierta incomodidad, aún más si consideramos que el inciso siguiente prevé que la "no abstención en los casos en que proceda dará lugar a responsabilidad"79. ¿Implica ello una presunción de responsabilidad, capaz de dar lugar a una indemnización de perjuicios? ¿Sobre quién recae esa responsabilidad, sobre el funcionario o sobre el Estado? Son cuestiones que dejamos planteadas entendiendo que exceden la materia regulatoria y que su respuesta debemos buscarla respecto del procedimiento administrativo chileno en general.

\section{Consideraciones finales}

La Ley №21.000 constituye un avance remarcable en cuanto al Gobierno de la Supervisión, pues al establecer la colegialidad, un sistema de elección de los comisionados en el que interviene tanto el ejecutivo como el legislativo, así como una remoción reglada y causada, se dota de mayor

\footnotetext{
75 En el Informe Final de la Comisión de Reforma a la Regulación y Supervisión Financiera se proponía una interdicción post empleo de una duración de 2 años. MINISTERIO DE HACIENDA (2011), p. 14. No obstante, el proyecto de ley enviado con fecha 2 de julio de 2013 no hacía referencia a la materia.

${ }^{76}$ Solo a modo ejemplar, la remuneración del gerente de Norte Grande S.A, sancionado en virtud del caso Cascadas alcanzaba los US 300.000. de acuerdo con lo expresado en la Junta ordinaria de accionistas de Norte Grande S.A. de 29 de abril de 2014.

${ }^{77}$ Art. 12 de la Ley № 19.880, de 2003.

${ }^{78}$ Art. 12 de la Ley № 19.880, de 2003.

${ }^{79}$ Art. 12 de la Ley № 19.880, de 2003.
} 
independencia al regulador respecto del primero, lo que constituía una de las principales objeciones que se formulaban en relación con la SVS. En ese sentido el diseño establecido por la Ley constituye un salto regulatorio que permite considerar a nuestra legislación como ajustada a los cánones internacionales. Respecto del financiamiento vía ley de presupuesto no podemos pronunciarnos aún pues no tenemos experiencia como país respecto de los manejos políticos que puede dar lugar la aprobación del presupuesto respecto de reguladores nombrados por dos poderes del Estado.

En cuanto a la captura por parte de intereses privados, lo óptimo hubiese sido que el legislador innovara recurriendo a la profesionalización vía inclusión de académicos, como se reclama también en otras latitudes, o bien aumentando progresivamente los estándares de probidad, oportunidad que no se aprovechó y que, junto con el plazo y las débiles sanciones a la infracción de las interdicciones post empleo, nos parece que son las principales falencias de la Ley № 21.000 .

Teniendo presente el tiempo y los recursos que el sector privado y público han invertido en el estudio de un correcto diseño de los reguladores económicos, esperamos que este tipo de consideraciones puedan ser también útiles al momento de perfeccionar la legislación atingente a los reguladores de otros sectores económicos o de otros países.

\section{BIBLIOGRAFÍA CITADA}

ARCULUS, DAVID (2005): "The Better Regulation Task Force", en: OECD, Designing Independent and Accountable Regulatory Authorities for High Quality Regulation. Disponible en: http://www.oecd.org/regreform/regulatory-policy/35028836.pdf [visitado el 08 de julio de 2018].

BALDWIN, ROBERT, CAVE, MARTIN Y LODGE, MARTIN (2012): Understanding Regulation: Theory, Strategy, and Practice, 2a edición (New York, Oxford University Press).

BALDWIN, ROBERT Y MAC CRUDDEN, CHRISTOPHER (1987): Regulation and Public Law (Law and Context) (Londres, Weidenfeld an Nicolson).

BERGOUGNOUX, JEAN (2000): Services publics en réseau: perspectives de concurrence et nouvelles régulations: Rapport du groupe présidé par Jean Bergougnoux (Paris, La documentation française).

BERMÚDEZ, JORGE (2013): "Fundamento y límites de la potestad sancionadora administrativa en materia ambiental", en: Revista de Derecho (№ 40), pp. 421-447.

BOURETZ, EMMANUELLE (2009): "La défaillance de la régulation financière", en: Revue de droit bancaire et financier ( $\left.\mathrm{N}^{\circ} 5\right)$, pp. 65-72.

CAMACHO CEPEDA, GLADYS (2005): "La problemática de la potestad normativa de las Superintendencias", en: A.A.V.V., Actas XXXIV Jornadas de Derecho Público (Santiago, LexisNexis), pp. 423-432.

CORDERO QUINZACARA, EDUARDO (2012): "La Administración del Estado en Chile y el concepto de autonomía”. Disponible en: https://www.contraloria.cl/documents/451102/1902464/85+a\%C3\%B1os.pdf/95421b18-9a16050d-335d-56f67b68b436. [visitado el 8 de julio de 2018]. 
(2013): "Sanciones administrativas y mercados regulados", en: Revista de Derecho (№ 1), pp. 119-144.

(2014): Derecho Administrativo Sancionador: bases y principios en el derecho chileno (Santiago, Legal Publishing/Thomson Reuters).

SOTO DELGADO, PABLO (2016): "Sanciones administrativas como medidas de cumplimiento del Derecho: un enfoque funcional y responsivo aplicado al régimen sancionatorio ambiental", en: Revista lus et Praxis (Vol. 22, № 2), pp. 189-226.

DE FARJAT, GÉRARD (2004): Pour un droit économique (Paris, PUF).

(2000): "Les pouvoirs privés économiques", en: A.A.V.V., Souveraineté étatique et marchés internationaux à la fin du XXe siècle, À propos de 30 ans de recherche du CREDIMI, Mélanges dans I'honneur de Philippe Khan (Dijon, Litec), pp. 213-662.

DÍAZ BRAVO, ENRIQUE (2012): "Desarrollo histórico del Principio de Separación de Poderes", en: Revista de Derecho (№ 38), pp. 240-270.

díAZ DE VALDÉS J., JOSÉ MANUEL (2010): "Anomalías Constitucionales de las Superintendencias: Un Diagnóstico", en: Estudios Constitucionales (Año 8, № 1), pp. 249-282.

FRISON-ROCHE, MARIE-ANNE (1995): "Le cadre juridique de la mondialisation des marchés financiers, Réflexions générales”, en: Banque et Droit (mai-juin), pp. 46-49.

(2011): Les 100 mots de la Régulación, ¿Collection Que sais-je? (Paris, PUF).

DU MARAIS, BERTRAND (2009): “Crise de la régulation ou capture du régulateur?". Disponible en: https://www.aef.asso.fr/publications/rapport-moral-sur-l-argent-dans-le-monde/rapport-moral2009/crise-de-la-r-eacute-gulation-ou-laquo-capture-du-r-eacute-gulateur-raquo. [visitado el 08 de julio de 2018].

garcía garcía, José, Verdugo ramírez, Sergio (2009): "Superintendencias en Tiempos de Cambio". Disponible en: http://www.lyd.com/lyd/controls/neochannels/neo_ch3757/deploy/tp948redisenodesuper.pdf. [visitado el 28 de enero de 2010].

GARCÍA GARCÍA, JOSÉ (2009): “¿Inflación de Superintendencias?: Un diagnóstico crítico desde el derecho regulatorio", en: Actualidad Jurídica (№ 9), pp. 327-372.

GARCíA GARCíA, José Y VERDUGO RAMÍREZ, SERGIO (2010): "De las superintendencias a las agencias regulatorias independientes en Chile: Aspectos constitucionales y de diseño regulatorio", en: Actualidad Jurídica (N²2), pp. 263-305. 
GARCÍA GARCÍA, JOSÉ Y SOTO VELASCO, SEBASTIÁN (2009): "Una mirada económica al diseño constitucional chileno: impacto sobre el proceso legislativo y la acción de los grupos de interés", en: Revista lus et Praxis (Vol. 15, N²), pp. 353-372.

GARRIDO FALLA, FERNANDO (1959): "Los medios de policía y la teoría de las sanciones administrativas", en: Revista de Administración Pública (№ 28), pp. 11-50.

GARRIDO FALLA, FERNANDO Y MONDACA, ALBERTO (1959): "Significado y técnica jurídica de la policía administrativa”, en: Revista de Administración Pública (№ 28), pp. 54-118.

ICT (EN LíNEA): “Módulo 6, sobre marco institucional y legal, párrafo, 6.5.1.2 FINANCIAL INDEPENDENCE". Disponible en: http://www.ictregulationtoolkit.org/toolkit/6.5. [visitado el 14 de abril de 2018].

JACOBZONE, STEPHANE (2005): "Independent Regulatory Agencies in OECD Countries: An Overview", en: OCDE Working Party on Regulatory Management and Reform. Designing Independent and Accountable Regulatory Authorities for High Quality Regulation. Disponible en: http://www.oecd.org/regreform/regulatory-policy/35028836.pdf [visitado el 08 de julio de 2018].

(EN LÍNEA): "Designing Independent and Accountable Regulatory Authorities: A Comparative Overview Across OECD Countries". Disponible en: http://www.oecd.org [visitado el 23 de julio de 2018].

LARRAÍN, MATÍAS (2014): "Les habits neufs du régulateur: analyse du projet d'une nouvelle institution financière au Chili", en: International review of financial services (№ 1), pp. 97-101.

(2010): "Notas al último intento de reforma del sistema de supervisión financiera", en: Anuario de Derecho Público UDP (N¹), pp. 392-414.

LIBERTAD Y DESARRollo (2009): "Superintendencias en Tiempos de Cambio". Disponible en: http://www.lyd.com/lyd/controls/neochannels/neo_ch3757/

deploy/tp948redisenodesuper.pdf._[visitado el 28 de enero de 2010].

MASCINDARO, DONATO, VEGA, ROSARIA Y QUINTYN, MARC (2011): "The Economic Crisis: Did Financial Supervision Matter?", en: Working Paper, WP/11/261 (Fondo Monetario Internacional).Disponible en: https://www.imf.org/external/pubs/ft/wp/2011/wp11261.pdf [visitado el 08 de junio de 2018].

MINISTERIO DE HACIENDA (2011): "Informe de la Comisión de Reforma a la Regulación y Supervisión Financiera". Disponible en: http://www.hacienda.cl/mercado-de-capitales/reforma-a-laregulacion-y-supervision.html. [visitado el 14 de abril de 2018].

(2015): "Informe del Grupo de trabajo para el fortalecimiento institucional del mercado de capitales. Informe de recomendaciones". Disponible en: http://www.hacienda.cl/mercado-decapitales/fortalecimiento-institucional-del/informe-con-propuestas-para-el.html. [visitado el 23 de julio de 2018]. 
(2010): "Informe de comisión especial investigadora de la cámara de diputados". Disponible en: https://www.camara.cl/sala/doc2.aspx?DOCID=1940. [visitado el 8 de junio de 2018].

(2008): "Estado de la Hacienda Pública". Disponible en: http://bibliotecadigital.dipres.gob.cl/bitstream/handle/11626/7682/Estado_Hacienda_Publica_20 08.pdf?sequence=2\&isAllowed=y [visitado el 08 de junio de 2018] .

MONDACA, ALBERTO (1959): "Significado y técnica jurídica de la policía administrativa", en: Revista de Administración Pública (№ 28), pp. 54-118.

MORALES LÓPEZ, DIEGO (2018): "Comisión para el mercado financiero: un cambio en la arquitectura de supervisión financiera en Chile", en: Estudios Públicos (№ 150), pp. 75-125.

OCDE (2017A): “¿Cuándo y por qué es necesaria a independencia y por qué se necesita esta guía?". Disponible en: https://read.oecd-ilibrary.org/governance/creando-una-cultura-deindependencia/cuando-y-por-que-es-necesaria-la-independencia-y-por-que-se-necesita-estaguia_9789264287877-5-es\#page1 [visitado el 08 de junio de 2018].

(2017B): "Guía para crear una cultura de independencia". Disponible en: https://read.oecdilibrary.org/governance/creando-una-cultura-de-independencia/guia-para-crear-una-cultura-deindependencia_9789264287877-6-es\#page1 [visitado el 08 de junio de 2018].

PIERRY ARRAU, PEDRO (1986): "La Administración del Estado en la Constitución Política", en: Revista de Derecho de la Pontificia Universidad Católica de Valparaíso (№ 10), pp. 411-433

POSER, NORMAN S. (2009): "Why the SEC Failed: Regulators Against Regulation". Disponible en: http://ssrn.com/abstract=1348612._[visitado el 23 de julio de 2018].

RAMÍREZ, STEVEN (2000): “Depoliticizing Financial Regulation", en: William and Mary Law Review (Vol. 41), pp. 503-593.

ROMÁN CORDERO, CRISTIÁN (2007): "Los principios del derecho administrativo sancionador", en: Revista de Derecho Público (№ 69), pp. 24-35.

SOTO DELGADO, PABLO (2016): "Sanciones administrativas como medidas de cumplimiento del Derecho: un enfoque funcional y responsivo aplicado al régimen sancionatorio ambiental", en: Revista lus et Praxis (Año 22, № 2), pp. 189-226.

SUPERINTENDENCIA DE VALORES Y SEGUROS (2008): “Comisión de Valores y Seguros. Una reforma para impulsar el crecimiento, la transparencia y el mejor gobierno del mercado de capitales". Disponible en: http://www.cmfchile.cl/portal/publicaciones/610/articles-16504_doc_pdf.pdf. [visitado el 9 de mayo de 2018].

VALLEJO GARRETÓN, RODRIGO Y GUILOFF TITIUN, MATÍAS (S/D): Ni juez, ni parte: La potestad sancionadora de la Administración y la metodología del derecho administrativo (Inédito). 
VALPUESTA ARÍSTEGUI, RAÚl Y PÉREZ ARIAS, PABLO (2013): "Repertorio de Jurisprudencia Administrativa de la Ley № 19.880, "Bases de los Procedimientos Administrativos que rigen los actos de los Órganos de la Administración del Estado". Disponible en: http://repositorio.uchile.cl/bitstream/handle/2250/116224/de36-Valpuesta_Raul.pdf?sequence=1 [visitado el 12 de junio de 2018].

VILLABLANCA CERDA, LUSITANIA (2011): "La metodología de la regulación. La lectura francesa aplicada al derecho comparado", en: Revista de Derecho y Ciencias Penales (№ 16), pp. 77-88.

(2011): "Organización del regulador de los mercados financieros. Derecho comparado", en: Actualidad Jurídica (№ 24), pp. 297-394.

(2012): "Las nuevas formas de regulación en el mercado financiero chileno", en: A.A.V.V, Estudios de Derecho Comercial (Santiago, Universidad de Chile), pp. 85-99.

\section{JURISPRUDENCIA CITADA}

CONTROL DE CONSTITUCIONALIDAD RESPECTO DEL PROYECTO DE LEY QUE CREA LA SUPERINTENDENCIA DE INSTITUCIONES DE SALUD PREVISIONAL, dicta normas para el otorgamiento de prestaciones por Isapres y deroga el D.F.L. № 3, de salud, de 1981 (1990): Tribunal Constitucional 15 de enero de 1990 (control de constitucionalidad), en: http://www.tribunalconstitucional.cl/expedientes?rol=92.

CONTROL DE CONSTITUCIONALIDAD DEL PROYECTO DE LEY QUE CREA EL SISTEMA DE PENSIONES SOLIDARIAS, mOdifica la institucionalidad para tal efecto, incorpora cambios al sistema de pensiones del Decreto Ley 3.500 de 1980 y materias relacionadas (2008): Tribunal Constitucional 4 de marzo de 2008 (control de constitucionalidad), en: http://www.tribunalconstitucional.cl/expedientes?rol=1032.

CONTROL DE CONSTITUCIONALIDAD DEL PROYECTO DE LEY SOBRE ACCESO A LA INFORMACIÓN PÚBLICA (2008): Tribunal Constitucional 10 de julio de 2008 (control de constitucionalidad), en: http://www.tribunalconstitucional.cl/expedientes?rol=1051.

DICTAMEN CGR № 34.935 de 2011.

DICTAMEN CGR № 15.860 de 2012.

DICTAMEN CGR № 58.558 de 2012.

OFICIO RESERVADO SVS № 6546 de 2013.

SVs, Oficio Reservado № 6546 de 2013.

RESOLUCIÓN SVS N²23 de 2 de septiembre de 2014.

RESOLUCIÓN SBIF № 16.191 de 30 de diciembre de 2015. 
JULIO PONCE LEROU RESPECTO DEL INCISO PRIMERO DEL ARTíCULO 29 DEL D.L. №3.538, de 1980, Ley Orgánica de la Superintendencia de Valores y Seguros, en la causa rol N 7250-2016 de la Corte de Apelaciones de Santiago (2016): Tribunal Constitucional 24 de mayo (2018) (requerimiento de inconstitucionalidad), en: http://www.tribunalconstitucional.cl/expedientes?rol=3236.

\section{NORMAS JURÍDICAS CITADAS}

CONVENCIÓN DE LA NACIONES UNIDAS CONTRA LA CORRUPCIÓN, Resolución 58/4 de la Asamblea General, 31 de octubre de 2003.

CONSTITUCIÓN POLÍTICA DE LA REPÚBLICA. Diario Oficial, 22 de septiembre de 2005.

LEY № 18.045, Ley de Mercado de Valores. Diario Oficial, 22 de octubre de 1985.

LEY № 18.046, Ley sobre Sociedades Anónimas. Diario Oficial, 22 de octubre de 1985.

LEY № 19.880, que establece las bases sobre los procedimientos administrativos que rigen los actos de la administración del Estado. Diario Oficial, 29 de mayo de 2003.

LEY № 20.880, sobre probidad en la función pública. Diario Oficial, 5 de enero de 2016.

DL N²11, que fija normas para la defensa de la libre competencia. Diario Oficial, 22 de diciembre de 1973.

DFL No 10 DEL MINISTERIO DE HACIENDA. Diario Oficial, 13 de diciembre de 2017.

DFL N 3 DEL MINISTERIO DE HACIENDA, LEY GENERAL DE BANCOS. Diario Oficial, 29 de diciembre de 1997.

LEY № 19.886, Ley de bases sobre contratos administrativos de suministro y prestación de servicios. Diario Oficial, 30 julio de 2003.

LEY № 19.996, modifica la Ley №19.039, sobre Propiedad Industrial. Diario Oficial, 19 de marzo de 2005.

LEY № 20.322, fortalece y perfecciona la jurisdicción tributaria y aduanera. Diario Oficial, 27 de enero de 2009.

LEY № 21.000, Crea la Comisión para el mercado financiero. Diario Oficial, 23 de febrero de 2017.

LEY № 21.130, moderniza la legislación bancaria. Diario Oficial, 12 de enero de 2019.

LOI 2017-55 (20/012017 portant statut général des autorités administratives indépendantes et des autorités publiques indépendantes.

CODE OF FEDERAL REGULATION (eCFR). 
MENSAJE DE LA LEY № 21.000 .

MENSAJE DE LA LEY № 20.880 . 